\title{
The Trust Levels, Trust Determinants, and Spatial Dimensions in Inter-Firm Relationships: A Warehousing Firm's Perspective in the City of Busan, South Korea
}

\author{
Sinje Sung ${ }^{1}$, Sangmok Kang ${ }^{2 *}$ \\ ${ }^{1}$ Department of Geography, University of Connecticut, Storrs, USA; ${ }^{2}$ Department of Economics, College of Economics and International \\ Trade, Pusan National University, Busan, South Korea. \\ Email: "smkang@pusan.ac.kr
}

Received November $1^{\text {st }}, 2012$; revised November $28^{\text {th }}, 2012$; accepted December $6^{\text {th }}, 2012$

\begin{abstract}
This study analyzes the trust level relationships of the warehousing industry firms in the city of Busan, South Korea in regards to their determinants and spatial dimensions. A firm's environment, such as reputation and renown, forms the relationship between the firm and other firms. The trust levels between firms were determined by the determinants of the trust: Long-term and repeated interaction, information sharing and reciprocity, and interdependence and asset specificity all had an important effect upon the micro or highest level of trust. Proximity and uncertainty influenced the meso or middle level of trust. The culture and norms of the firms \& institutional formality affected the macro or lowest level of trust. It was found that the higher the trust levels, the more the respective spatial dimensions generated by the relationship between firms expanded to the national and international dimensions.
\end{abstract}

Keywords: Trust Levels; Determinants of the Trust; Spatial Dimensions; Warehouse Firms; Busan

\section{Introduction}

Studies on trust began in earnest in the mid 1980's. The topics on trust have attracted increasing attention, inspiring diverse studies into various other disciplines. Specifically, most trust studies focused on the relationships between firms have insisted that trust is a most important tool that firms should use to enhance their competitive advantage in three ways:

First, the trust between firms enhances flexibility and adaptability so that firms can quickly react in a rapidly changing economic environment. This is because trust fosters successful collaborations between firms [1,2]. In fact, it is especially important in enabling firms to reduce the time and costs encountered in the process of negotiations, agreements, or monitoring when swift decisions need to be made. The reason trust is important is because the firms could miss new opportunities by spending too much time in contract negotiations due to a lack of trust.

Second, trust lets firms learn and innovate through "know-how" sharing between firms [3-6]. One of the important purposes in building relationships between firms is to develop know-how regarding management and technologies through trading firms. The firms

*Corresponding author. create innovation by combining their own know-how with the know-how from other trading firms.

Third, trust can achieve a higher synergy between firms [7-9]. Firms try to focus on the specialization of their core competencies, and to complement all other aspects through inter-firm relationships. The firms that make up the complementary relationships can foster synergy by integrating their mutual core competencies through trust relationships.

Existing studies, however, mainly focus on exploring complex economic or social phenomenon based on trust in the relationships between firms. They have failed to explain the series of continuous processes regarding trust levels or development in the relationships between firms. Moreover, these studies are significantly limited in showing the influence of the determinants and spatial characteristics associated with the trust levels between firms.

Recently, studies on supply chain management show that trust is a most important factor in a variety of ways [10-15]. The purpose of supply chain management is to accelerate the movement of goods, ensure the delivery of the correct goods to the correct place at the correct time, and in doing so lower the cost of transportation [16]. In supply chain management, the role of logistics firms is to offer the solutions needed to reconcile their mistaken 
goals. Most of these solutions have been greatly relied upon in the warehousing industry [17]. This is because the warehousing industry plays the coordinating role in transferring the necessary amount of goods to a specific place at the correct time through inter-firm relationships $[17,18]$. Therefore, the trust levels between these firms are closely related regarding whether or not the firms achieve a successful supply chain management $[19,20]$. As a result, a close correlation exists between the performance of supply chain management and trust levels. Specifically, trust levels between warehouse firms and trading firms regarding supply chain management play a most decisive role in maximizing the efficiency of supply chain management. Accordingly, it is important to better understand the mechanisms forming these trust levels and development processes. The mechanisms include how a trust level can be built and improved, where the trust level is situated, why it stays at a particular level, what determinants influence the trust levels in the relationships between warehouse firm and their trading firms, and so on. However, there has been little academic and empirical research examining on them.

The purpose of this paper is to analyze trust levels in order to find their determinants and spatial dimensions in inter-firm relationships and to better grasp how to create and develop trust in distinct times and places. In order to address this, this paper attempts to achieve the following concrete objectives:

1) Identify the trust levels and development stages and investigate their determinants in inter-firm relationship.

2) Analyze the influences of the determinants and differences of spatial dimensions according to the trust levels.

The most significant contribution of this paper is to determine the development processes and differences of trust levels through the dynamic perspective regarding how trust is built where and or why it is constructed and situated in particular times and spaces.

\section{Theoretical Framework}

\subsection{Trust Levels and Development Stages}

Disciplinary differences characterizing the traditional treatment of the trust building process between firms suggest that inherent conflicts and divergent assumptions are at work. Despite the complex character of trust, however, previous research suggests that trust building processes between firms may drive and shape by influence at three levels: the macro level, the meso level, and the micro level [21-23].

The macro level trust may be linked to Sako's (1992) contractual trust. As contractual trust pertains to a kind of agreement documented between firms, if the contractual firms do not comply to this type of agreement they are subjected to legal sanctions. In this context, the macro level trust is similar to the calculus-based trust of Lewicki and Bunker (1996) and the macro scale trust (the structural or institutional) by Murphy (2006). Accordingly, the macro level trust rests on beliefs in formal norms and institutions or in the ability to govern them. At the macro level trust, it refers to formal institutional arrangements [24].

The meso level trust corresponds to Sako's (1992) competence trust. The competence trust is the process determined through trade whether or not the trading firm has the ability to carry out agreements. Therefore, the meso level trust is based on face to face or person to person encounters and ascriptions (race, religion, speech, ethnicity, etc.) [25]. The meso level trust can be considered as the knowledge-based trust conceptualized by Lewicki and Bunker (1996) and the meso scale trust (intersubjective) by Murphy (2006) because these trusts have a major interest in the process, being progressively realized through interactions [26].

The micro level trust may be linked to Sako's (1992) goodwill trust. The goodwill trust is determined by the mutual expectations of an open commitment to maintain the relationship. The cooperation willingness between firms includes formally agreed or stipulated contracts in the trust. In this regard, the micro level trust is a subjective interpretation of shared experiences and observed competences through trade over time. The identificationbased trust discussed by Lewicki and Bunker (1996) and the micro scale trust (the subjective) can be understood in the same context, because firms have a strong emotional component for understanding, appreciation, and individual interpretations [27].

Trust level influences the quality or strength of particular association between firms [23]. Sako (1992) identified the development process used for trust levels. That is, contractual trust needs to be established prior to competence trust which in turn leads to the development of goodwill trust. Similarly to Sako (1992), Lewicki and Bunker (1996) also defined that the stages of trust level gradually move from calculus-based trust to knowledgebased trust, and then identification-based trust. Ultimately, the trust levels in inter-firm relationships develop from the macro level through the meso level to the micro level.

Meanwhile, Murphy (2006) described the firms' environment as the rationale building relationship between firms. The rationales may be connected to the need to access resources, technology, and knowledge transfer processes, or the desire to build a reputation [6,25].

Based on the above studies, considering the building and development of trust as a continuous process, we 
present a conceptualization that consists of the macro level, the meso level, the micro level, and firm's environment. That is, once the relationship between firms is built by their environment, their trust levels gradually develop from the macro level to the meso level and then to the micro level. Also, development steps regarding the three trust levels are likely to be definite such as Figure 1.

The first step is the macro level of trust. While this step is dominated by an opportunistic environment, the firm is assured of their legal rights from the other trading firms. The macro level appears to be mainly made up of contracted forms based on institutions, norms, regulations, etc. Thus, a firm's non-fulfillment of the agreement entails sanctions in this level of trust. The macro level is the minimal form of trust because it is made up of official contracts or agreements under an opportunistic environment.

The second step is the meso level of trust. This allows a firm to further interact with the trading firm in order to achieve stability. In this step, the firm can predict the behavior of the trading firm, and relies on the observation of the trading firm. The meso level is the process step of trust. By communicating their subjects to the partner firms, the firms continuously adjust their perception of the partners.

The third step is the micro level of trust. In this step, the firm has a strong willingness to increase mutual understanding with open commitments to the trading firm. The firms willingly accept cooperation requests under the micro level built between firms, and find a way to solve problems together. The micro level is the maximal level of trust because the firms have a great determination to conduct not only formal but also informal contracts.

\subsection{Determinants of Trust}

As shown in Table 1, based on previous research on determinants of trust, the following determinants are likely to influence the characteristics of trust between firms: 1)

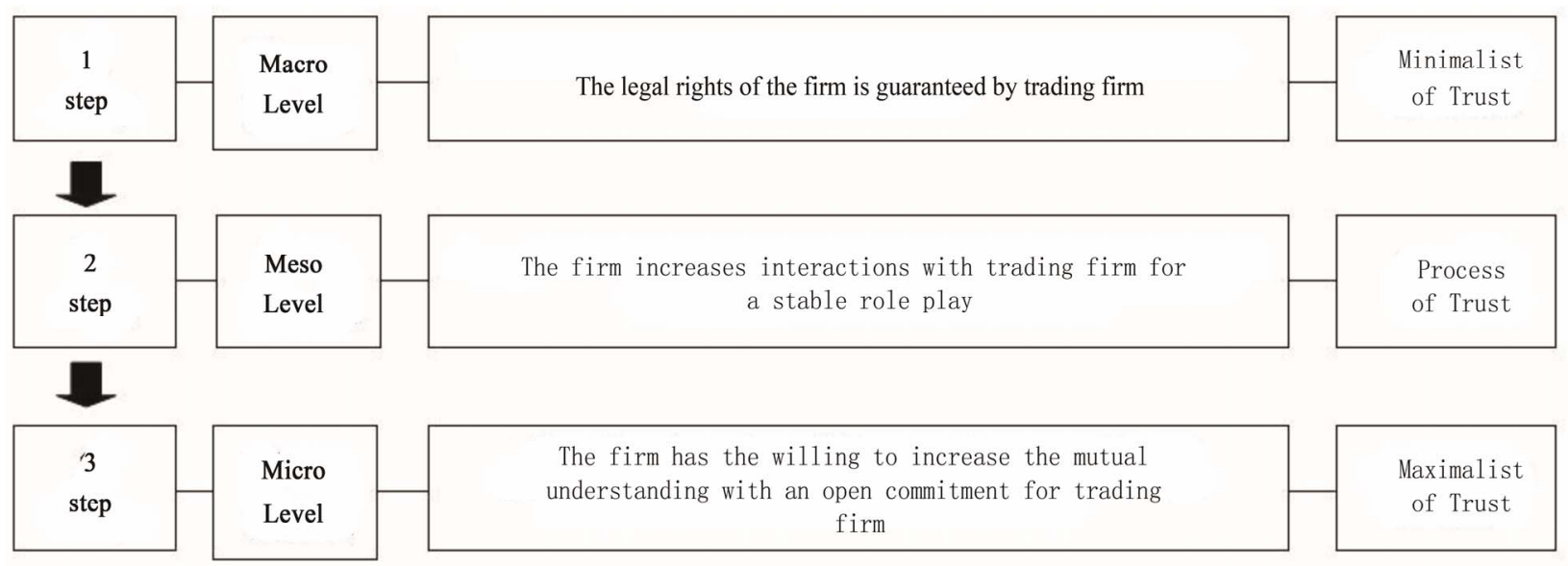

Figure 1. The definition and development of trust levels.

Table 1. Previous research on determinants of trust.

\begin{tabular}{ll}
\hline Determinants of trust & Previous research \\
\hline $\begin{array}{l}\text { Long-term and repeated } \\
\text { interactions }\end{array}$ & $\begin{array}{l}\text { Axelrod (1984), Granovetter (1985), Zucker (1986), Kreps (1990), } \\
\text { Aulakh et al. (1996), Sako and Helper (1998) }\end{array}$ \\
$\begin{array}{l}\text { Interdependence, } \\
\text { Asset specificity }\end{array}$ & $\begin{array}{l}\text { Williamson (1985), Bradach and Eccles (1989), Morgan and Hunter (1994), Lusch and } \\
\text { Brown (1996), Dyer and Singh (1998) }\end{array}$ \\
$\begin{array}{l}\text { Information sharing, } \\
\text { Reciprocity }\end{array}$ & $\begin{array}{l}\text { Ekeh (1974), Zucker (1986), Aoki(1990), Nelson and Cooprider (1996), Doz and Hamel (1998), } \\
\text { Uncertainty }\end{array}$ \\
$\begin{array}{l}\text { Walker and Weber (1984), Zucker (1986) } \\
\text { Proximity }\end{array}$ \\
$\begin{array}{l}\text { Beveridge (1985), Zucker(1986), Daniel } \text { et al.(1995), Cooke and Morgan (1998), Wellman and } \\
\text { Milena (1999), MacKinnon } \text { et al. (2002), }\end{array}$ \\
$\begin{array}{l}\text { Culture and the norms } \\
\text { of firms, Formal institution }\end{array}$
\end{tabular}


long-term and repeated interactions; 2) information sharing and reciprocity; 3 ) interdependence and asset specificity; 4) uncertainty; 5) proximity; and 6) cultures and norms of firms \& formal institutions. In the following section we explore each of these determinants in more detail.

\subsubsection{Long-Term and Repeated Interactions}

Axelrod (1984) argued that the trust level may gradually be higher when firms repeatedly interact over the long term. That is, even though transactions between firms were opportunistic, if their transactions can last for longer periods, trust between them may build and develop. In game theory, whereas a one shot game brings one to the "prisoner's dilemma" situation, relationships when the game lasts a long time develop trust building aspects [28, 29]. The "reputation effect" occurring in long-run and repeated games can have a similar impact on firm behavior. The reputation effect makes even selfish firms build trust, who then do not act in an opportunistic manner but cooperative through their calculations based on their long-term interests [29-31]. Zucker (1986) insisted that long-term and repeated interactions contribute to trust development by reducing uncertainties regarding the trends of their partner's behaviors. Exchange theorists posit that trust achieved through the repetition of mutual interaction is an essential element for societal stability [32,33].

Hypothesis 1: The longer and repeater interaction by the relationship between firms, the higher the trust levels between firms.

\subsubsection{Information Sharing and Reciprocity}

As is well-known in agency theory, the biggest obstacle in trust development is an asymmetry in the information shared between firms. An information asymmetry between firms can expose vulnerabilities, which makes it difficult for a firm to trust the other firm and so deters trust building. Information sharing makes it easier to develop trust between firms because this sharing acts as one of the most important factors in understanding the true situations regarding the trading firms, such as behavior patterns, purposes, competencies, values, and incentives [34-36].

The sharing of sensitive information amongst partners can be a sign of trust for the trading firm. According to Aoki (1990), information sharing between firms had an effect on trust building in Japan, enabling more cooperation in Japans' firms than that found for US firms. Under asymmetrical information sharing situations between firms, reciprocity becomes a very important factor in trust development. Reciprocity implies that if a firm gains trust from a trading firm, the firm also has a higher possibility to reciprocally trust the trading firm. In general, information sharing strengthens trust building based on reciprocity. In turn, trust strengthens information sharing between firms.

Hypothesis 2: The more information sharing and reciprocity by the relationship between firms, the higher the trust levels between firms.

\subsubsection{Interdependence and Asset Specificity}

Interdependence between firms is a key aspect in trust development [37]. When a relationship between firms is interdependent, the firms enhance their asset specificity. High asset specificity makes the relationship between firms interdependent on the basis of trust. If the relationship does not maintain interdependence, the firms become strapped by bearing high switching costs due to their asset specificity. Therefore, they need to maintain an interdependent relationship, which increases the trust level [38-40]. After all, since high asset specificity enhances inter-firm trust, firms become more dedicated in their commitments each other.

However, in the case where the relationship between firms is not interdependent or particularly one-sided it becomes difficult to develop trust between firms, because the firms in this situation can indulge in opportunistic behaviors [39,41]. Since the firms have a high risk of opportunism in this case, they use leading terms, such as "credible commitment" or "hostages" to improve the trust between firms $[9,42,43]$.

Hypothesis 3: The more interdependence and asset specificity by the relationship between firms, the higher the trust levels between firms.

\subsubsection{Uncertainty}

Uncertainty in the economic environment of a firm creates opportunism [44]. The higher the degree of uncertainty, the greater trust benefits transactions, because trust facilitates decision making and reduces opportunistic behavior in unanticipated circumstances. In the trust relationship built between firms, the firms believe that their partners will undertake behaviors in predictable directions. Therefore, trust may be useful in lowering the behavioral uncertainty between firms [9]. Meanwhile, uncertainty is not only an obstacle that makes it harder for cooperation between firms but also a cause that incurs high transaction costs, even though the firms have useful ideas that could create an attainable value through interfirm relationships. For example, even though the firms have a chance to create new practical value through cooperation with a trading firm, the firms hesitate to invest when it is uncertain whether it is possible to maintain a continuous cooperation with the partner [45]. Trust between firms enables the creation of higher value by 
removing the uncertainty.

Hypothesis 4: The more uncertainty by the relationship between firms, the higher the trust levels between firms.

\subsubsection{Proximity}

Williamson (1985) states that geographical proximity is a key element in trust development. In this context, Daniel et al. (1995) provided evidence that the closer the physical distance of a factory between the supplier and customer, the grater the trust development in their relationship. As a result, geographical proximity may be useful in reducing their inventory and logistics costs. MacKinnon et al. (2002), which analyzed industrial districts, showed that geographical proximity facilitates trust development by increasing the formal and informal contacts between firms. In fact, the industrial districts formed on the basis of geographical proximity are closely related to the spatial interaction dimensions based on trust development [46].

At the same time, Wellman and Milena (1999) insisted that trust development is more likely affected by a social proximity rather than a physical proximity. That is, similarities in age, language, occupation, purpose, and common values let firms have a sense of community, stimulate inter-firm communication, and strengthen mutual ties, resulting in acceleration in trust between firms. Actually, similar values and behavior patterns which promote an emotional bond and intimacy between firms are able to remove many conflicts. Social proximity creates situations that make it easier to develop trust between firms.

Hypothesis 5: The proximity creates situations that make it easier to develop trust between firms.

\subsubsection{Culture and Norm of Firms \& Formal Institution}

Trust development between firms is closely related to the culture and norm of a firm and its formal institution [47]. For example, trust development has a more prevalent effect on the cultural norms of Japan due to reciprocity than those found for the United Kingdom and the United States on the basis of a competition [21,48]. In fact, as the norms such as trust can be called "the precipitate of history”, the cultural norms of a particular firm cannot be applied equally to other firms [21]. For instance, although the US automobile industry when it hit a crisis attempted to imitate the Japanese norms, there was much difficulty in the application of the path-dependent customer-supplier network developed in Japan [9].

Meanwhile, formal institution in regards to the complexity of the business environment has a large effect on trust development between firms [31,49]. Regardless of a partner firm's reputation, formal and legal agreements between firms are modern society's generalized type of transaction based on trust. In addition, credit rating agencies along with credit card and bank credit reports confirm whether or not a firm is trustworthy. Formal institution therefore is presently the standard frame used to support trust development between firms.

Hypothesis 6: Trust levels between firms are closely related to the culture and norm of a firm and its formal institution.

\section{Methodology}

This study is an empirical test and makes use of both quantitative and qualitative methods. The data for quantitative method came from survey targeting 310 warehousing firms and the data for qualitative method came from in-depth interviews of three warehousing providers in the city of Busan, South Korea. The warehouse firms are distributed as shown in Figure 2.

First, we designed the survey questionnaire for the warehousing firms. The questions on trust levels between firms were developed using the three steps: macro trust, meso trust, and micro trust. The six determinants of trust, long-term and repeated interactions, information sharing and reciprocity, interdependence and asset specificity, uncertainty, proximity, and culture and the norms of firms \& formal institution, were designed as a 5-point Likert scale using the analytic hierarchy process (AHP) ${ }^{1}$.

The survey was done door to door for 310 warehouse providers from 25 July to 25 November, 2008. We also included an e-mail request to the warehouse firms. Of the 310 firms, 162 firms (53.6\%) responded to the questionnaires. However, we excluded 10 inappropriate questionnaires that contained errors, resulting in 152 valid responses.

As shown in Table 2, approximately 39.5\% of the firms answering the survey identified as General Warehousing; 33.6\% identified as Refrigerated Warehousing. In the respect to the firm size, small scale firms of less than 5 workers and 5 - 49 workers took a respective $40.1 \%$, accounting for almost $80.2 \%$ of the collected warehouse firms. Middle scale firms of 50 - 299 workers took at $17.1 \%$ and large scale firms of over 300 workers made up only $2.7 \%$.

From the standpoint of organization, single-unit firms, headquarters, and branches represented 48.0\%, 40.8\%, and $11.2 \%$, respectively. The establishment year of the firms were distributed as 38.8\% after 2001, 28.3\% between 1996 and 2000, 23.0\% from 1981-1995, and 9.9\% before 1980 .

In addition, we conducted in-depth interviews targeting three random warehouse firms in order to comple-

${ }^{1}$ Determinants were expressed by a 5-point Likert scale ( 1 = low impact 5 = high impact). 


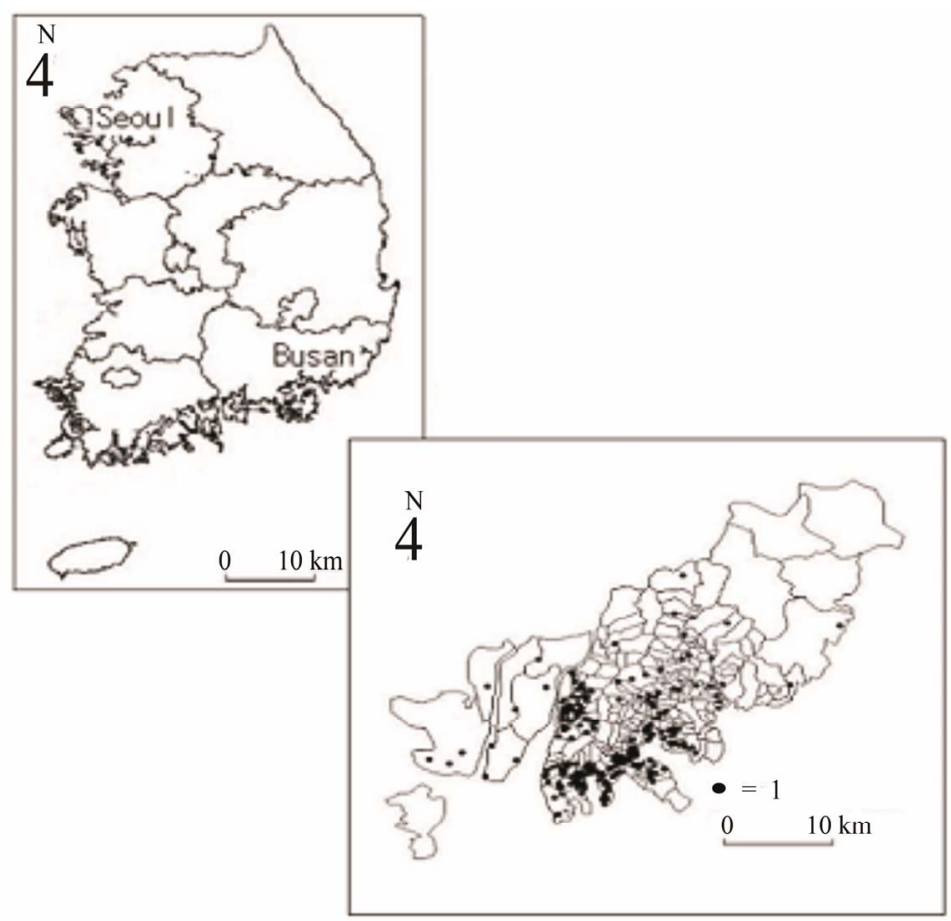

Figure 2. The distribution of the warehousing firms in Busan, South Korea.

Table 2. The profiles of the survey respondents.

\begin{tabular}{|c|c|c|c|c|}
\hline \multicolumn{2}{|c|}{ Characteristics } & Number of Population firms (A) & Number of Sample firms (B) & Ratio (B/A) \\
\hline \multirow{6}{*}{$\begin{array}{l}\text { Type of } \\
\text { Firms }\end{array}$} & General Warehousing & $152(42.0)$ & $60(39.5)$ & 39.5 \\
\hline & Refrigerated Warehousing & $74(23.9)$ & $51(33.6)$ & 68.9 \\
\hline & Farm products warehousing & $9(2.9)$ & $6(4.0)$ & 66.7 \\
\hline & Dangerous Goods Warehousing & $24(7.7)$ & $16(10.5)$ & 66.7 \\
\hline & Other Warehousing & $51(16.5)$ & $19(12.5)$ & 37.3 \\
\hline & total & $310(100.0)$ & $152(100.0)$ & 49.0 \\
\hline \multirow{5}{*}{ Firm Size } & $<5$ workers & $111(35.8)$ & $61(40.1)$ & 55.0 \\
\hline & 5 - 49 workers & 144 (46.5) & $61(40.1)$ & 42.4 \\
\hline & 50 - 299 workers & $51(16.5)$ & $26(17.1)$ & 51.0 \\
\hline & >299 workers & $4(1.3)$ & $4(2.7)$ & 100.0 \\
\hline & total & $310(100.0)$ & $152(100.0)$ & 49.0 \\
\hline \multirow{4}{*}{$\begin{array}{l}\text { Firm's Organizational } \\
\text { forms }\end{array}$} & Single-unit firm & $142(45.8)$ & $73(48.0)$ & 51.4 \\
\hline & Headquarters & 135 (43.6) & $62(40.8)$ & 45.9 \\
\hline & Branches & $33(10.7)$ & $17(11.2)$ & 51.5 \\
\hline & total & $310(100.0)$ & $152(100.0)$ & 49.0 \\
\hline \multirow{5}{*}{ Data of Establishments } & 1980s or earlier & $25(8.1)$ & $15(9.9)$ & 60.0 \\
\hline & 1981-1995s & 70 (22.6) & 35 (23.0) & 50.0 \\
\hline & 1996-2000s & $78(25.2)$ & $43(28.3)$ & 55.1 \\
\hline & 2001s or since & $137(44.2)$ & 59 (38.8) & 43.1 \\
\hline & Total & $310(100.0)$ & $152(100.0)$ & 49.0 \\
\hline
\end{tabular}


ing three random warehouse firms in order to complement the questionnaire survey. As shown in Table 3, we interviewed face to face three executive directors in charge of the offices at three warehousing firms. The average time of the in-depth interviews was around 130 minutes.

Second, we investigated the addresses and driving times regarding the survey firms and their trading firms in order to understand the differences the spatial dimensions contributed to the trust levels between firms. Using ArcView, we classified the spatial dimensions through the proximity analysis of inter-firm distances as follows: "the local dimension" (less then $10 \mathrm{~km}$ ), "the regional dimension" (more than $10 \mathrm{~km}$ less than $50 \mathrm{~km}$ ), "the metropolitan dimension" (more than $50 \mathrm{~km}$ less than 200 $\mathrm{km}$ ), "the national dimension" (more than $200 \mathrm{~km}$ less than $500 \mathrm{~km}$ ), and "the international dimension" (more than $500 \mathrm{~km})^{2}$.

\section{Results}

Before testing the differences and the effects of the determinants and the spatial dimensions on the trust levels, we evaluated the reliability and collinearity of the independent variables. First, we conducted a reliability analysis for all independent variables to confirm the consis- tency of the respondents. Cronbach's alpha $(\alpha)$ was 0.872 , implying acceptable reliability for all the scales. Second, we conducted a Pearson correlation analysis for each variable to determine the multicollinearity between the variables. As shown in Table 4, no correlation coefficient exceeded 0.5 , indicating no multicollinearity between the variables.

\subsection{The Inter-Firm Trust Levels and Determinants}

Figure 3 shows the substantially different results due to the influence of its determinants by the trust levels between firms. The three trust levels showed outstanding distinctions in the six determinants. The macro level resulted from "culture and norms of firms \& formal institution", whereas the meso level depended on "proximity" and "uncertainty". The micro level was influenced by "long-term and repeated interaction", "information sharing and reciprocity", and "interdependence and asset specificity". These results are supported by the additional in-depth interviews. One interviewee described these findings as follows:

"My firm has traded with a food and beverage processing firm (firm I) and seafood importing firms (firms II and III) for more than 10 years. The reason my firm

Table 3. The profiles of the three in-depth interviews.

\begin{tabular}{|c|c|c|c|c|}
\hline & Location & Establishment year & Number of trading firm & Date of interview \\
\hline 1 & Saha-gu in Busan & 1986 & 13 & October 2008 \\
\hline 2 & Yeongdo-gu in Busan & 1953 & 20 & October 2008 \\
\hline 3 & Nam-gu in Busan & 1967 & 22 & November 2008 \\
\hline
\end{tabular}

Table 4. Correlation matrix of measurements.

\begin{tabular}{cccccc}
\hline & A & B & C & D & E \\
\hline A & 1.000 & & & & \\
B & $0.402\left(^{* *}\right)$ & 1.000 & & & \\
C & $0.399\left(^{* *}\right)$ & $0.396\left(^{* *}\right)$ & 1.000 & & \\
D & $0.412\left(^{* *}\right)$ & $0.285\left(^{* *}\right)$ & $0.367\left(^{* *}\right)$ & 1.000 & 1.000 \\
E & $0.466\left(^{* *}\right)$ & $0.290\left(^{* *}\right)$ & $0.340\left(^{* *}\right)$ & $0.462\left(^{* *}\right)$ & $0.491\left(^{* *}\right)$ \\
F & $0.316\left(^{* *}\right)$ & $0.340\left(^{* *}\right)$ & $0.318\left(^{* *}\right)$ & $0.453\left(^{* *}\right)$ & 1.000 \\
\hline
\end{tabular}

Footnotes: a. A: long-term and repeated interactions; B: information sharing and reciprocity; C: interdependence and asset specificity, D: uncertainty, E: proximity; F: cultures and norms of firms and formal institutions; b. ${ }^{* *}$ Correlation is significant at the 0.01 level (2-tailed); c. ${ }^{*}$ Correlation is significant at the 0.05 level (2-tailed).

${ }^{2}$ Spatial dimensions were classified as less than 10 km, 10 - 50 km, 50 - 200 km, 200 - 500 km, and over 500 km. The mid-point of each interval was used, which used the values of $5,25,125,350$ and 750 , respectively. 
had built relationships with these firms at first was because of their reputation. After building a relationship, my firm wrote formal contracts in the initial period whenever we transacted due to low trust levels. However, we were able to have frequent meetings being geographically located very close to each other. Accordingly, as the uncertainty was removed through these formal and informal meetings with each other, information sharing and investment constantly increased. Now, all of our systems are assembled in regards to firms I, II, and III; we are highly interdependent. Therefore, my firm may face a serious crisis if these firms betray us. Firm I produces and processes food and beverage products, having been supplied with fishery goods from firms II and III. My firm provides firm I with warehousing services through supply chain management, and helps to form a seamless flow amongst firms I, II, and III, which can ultimately contribute to an increase in their efficiency. Although I do not write the formal contracts with these firms, whenever we do transactions, my firm automatically provides firms II and III with the fishery goods storage services and delivers the fishery goods to firm I. The contract documents with these firms are made at a time after the transaction, because we highly trust each other" (Saha-gu in Busan, October 2008).

The above interview supported the fact that a firm's reputation forms a relationship between the firms and the trust level depends in part on the effects of its determinants under the inter-firm relationship. The general picture is that the lower the trust level, such as the macro trust, the higher the uncertainty between firms due to short transaction periods, low information sharing, and asset specificity. Therefore, these firms always require an official agreement written in detail whenever transacting; this constitutes a safeguard against opportunistic behaveior by the trading firm. Meanwhile, geographical proximity plays a vital role on improving the trust level from the macro level to the meso level by fostering frequent interactions between firms and gradually removing the uncertainty. Long-term and repeated interaction, information sharing and reciprocity, and interdependence and asset specificity greatly influence the building of the micro level which is the high trust level between firms. If a good micro trust between firms is obtained, the firm does not consider drawing up of an agreement too seriously, believing that the trading firm will not engage in opportunistic behavior. They mostly make long-term contracts and draw up agreements in one time.

The firm's environment, such as reputation, creates relationships between firms [23]. Once building a relationship through reputation, the firm frequently has formal and informal communications with the trading firms to maintain their own reputation and remove uncertainty between them. The firm also invests in asset specificity to the trading firms as a sign of trust. Asset specificity increases the duties and responsibilities each other to maintain the relationship between the firms. This longterm and repeated interaction extends information sharing and grants the ability to handle their problems

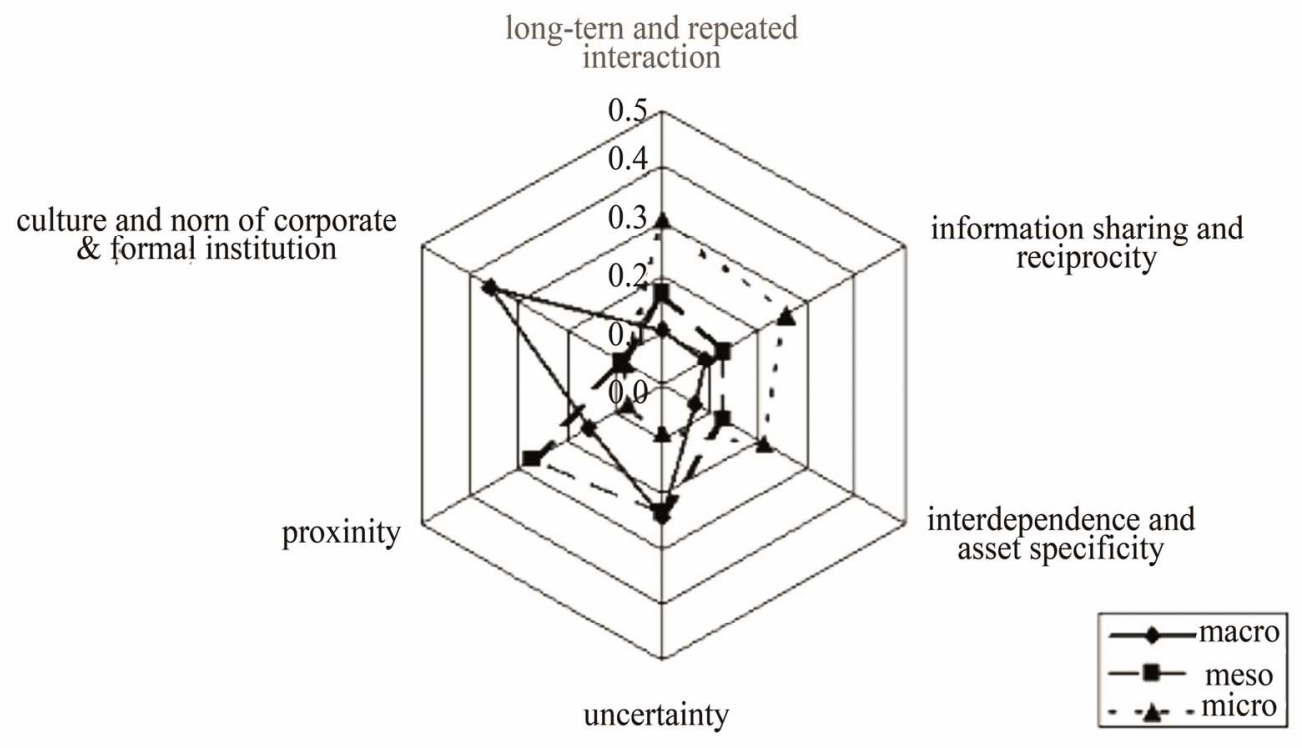

Figure 3. The trust levels and determinants of the warehousing firms in the city of Busan, South Korea.

\footnotetext{
${ }^{3}$ The city of Ulsan is a metropolitan city which has developed the automobile industry focused on the Hyundai.

4’'Dong” stands for the smallest administration district unit in South Korea.
} 
quickly. By doing so, they can maintain the trust at a high micro level. Where this process has been repeated, the degree of trust regarding partner firms created from reputation grows continuously; the firms then extend the spatial dimensions of their activities. The following interview supports this result:

"Since its establishment in 1953, my firm has constantly tried to obtain the latest equipment and to expand our service area. As a result, my firm was designated as a LME (London Metal Exchange) warehouse. My firm keeps a high trust level with an automobile firm located in city of Ulsan and provides the firm with the best service. ${ }^{3}$ For example, when assigning experts for the customer, my firm often meets with them and checks problems that can be solved cooperatively. My firm has won a high trust from the customer firms through these repeated efforts. Because of my firm's renown, my firm can transact with the firms located even in the capital city of Seoul and in Gyeonggi province. As a result, my firm could extend our market range up to the area of the capital city" (Yeongdo-gu in Busan, October 2008).

\subsection{Inter-Firm Trust Levels and Spatial Dimensions}

Figure 4 displays the differences in the spatial dimensions due to inter-firm trust levels. All trust levels of macro, meso, and micro, are overwhelmingly built in the dimension of local spaces. These are closely connected in conjunction with both dynamic and static agglomeration economics. That is, dynamic and static agglomeration economics can generate the external economics of a firm's activities. The external economics of a firm's activities refer to the construction of an inter-firm relationship based on the firm's environment, i.e., resource acquisition, technology or knowledge transfer, reputation, and renown. Therefore, this implies that the appearance of various trust levels in the local dimension results from the external effect of the firm's activities. As one interview participant stated:

"My firm outsourced our transportation function to firms IV and V. My firm takes advantage of just-in-time delivery, because firms IV and V are located in spatially close proximity to my firm. My firm has traded with firm IV since our establishment in 1953. In that time we have built a high trust level each other. In recent years, my firm began to transact with firm $\mathrm{V}$ due to the expansion of my firm. Therefore, my firm has built a lower trust level with firm $\mathrm{V}$ due to the short transaction period" (Yeongdo-gu in Busan, October 2008).

Meanwhile, the higher the trust levels from the macro level to the meso level, and gradually to the micro level, the more the spatial dimensions from the relationships between firms expand from the local to the national, and to the international dimensions, respectively. The following interview confirms this:

"My firm (firm P) has traded with firm VIII, working in processed foods and beverages, over the last 10 years. Firm VIII, being a branch of firm I, was established 10 years ago. We have built a high level of trust, i.e. micro trust. My firm and firm I are located in a same local space dimension, 'dong'. ${ }^{4}$ Since firm I established its branches in the capital city, Seoul, my firm has built a high micro trust level with firm I. Firm I trusted my firm at that time, and so introduced my firm to firm VIII. By doing so, my firm expanded its trading dimension to the capital area" (Saha-gu in Busan, October 2008).

In the in-depth interview mentioned above, it was confirmed that since firm $\mathrm{P}$ built a high micro level trust with firm I a long time ago, firm P had an opportunity to build a relationship with firm VIII in Seoul. This implies that if the trust level between firms is high, the firms may introduce their partner to other firms. That is, a high trust level can create new customers and expand the spatial dimensions between firms by offsetting the frictional forces of distance.

Our interviews also suggest that trust levels play important roles in a firm's globalization. If the firm has renowned from the result of trust building, the firm has a high probability in building relationships with foreign firms. The service level and the trustworthiness of the firm are the core criterions in which foreign firms employ when looking for partner firms in applicable target areas [50]. In fact, the service level of a firm is a "black box", which is difficult to evaluate or to experience before purchasing. The foreign firms that are going to purchase the "black box" service have no choice but to rely on the firm providing the service because their information regarding the service is vulnerable. The higher the renown of a firm, the greater the probability of building an inter-firm relationship. In fact, a high renown in the firm indirectly proves that the firm has obtained trust from many firms. This is supported by a next interview:

"Warehousing is a part of logistic firm's geographically based services, which is a large proportion of transaction and logistic costs. Warehousing is a key element in the supply management chain. A new warehousing market is closely related to the growth of logistic firms. My firm as a warehousing firm started business with the USA in 1986 and the China in 1988. When my firm entered into these areas, other international firms had already advanced into many parts of these markets in the middle of 1980's. The American market favored American logistic firms and the China market had embraced American and European firms. International firms want to outsource warehousing to Korean firms that had a geographical and functional specialize- 


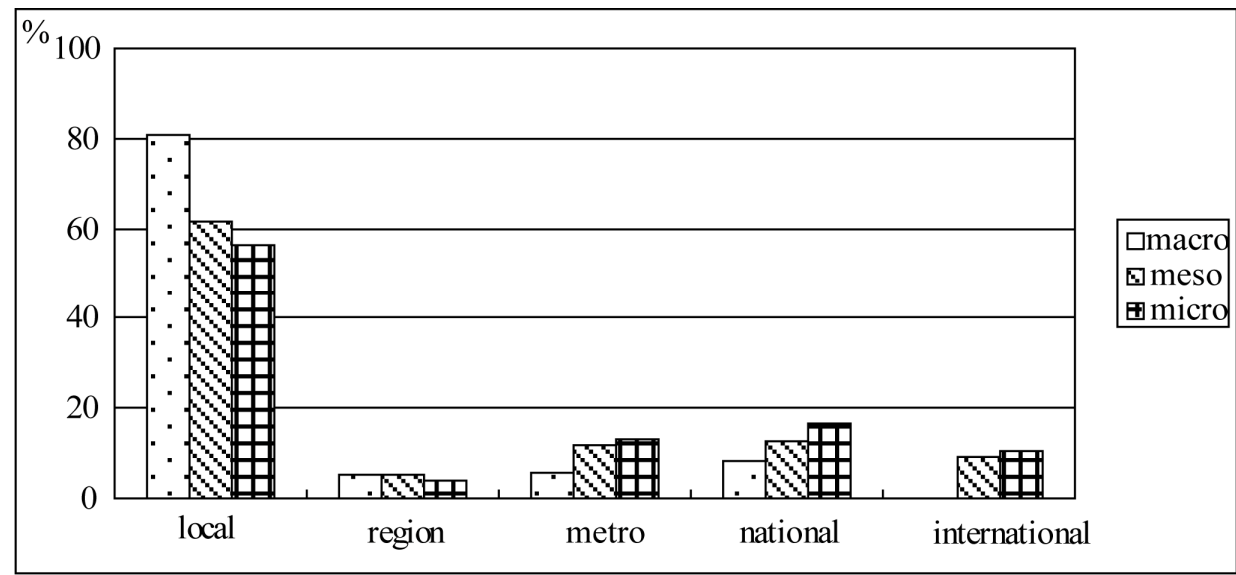

Figure 4. The trust levels and spatial dimensions of the warehousing firms in Busan, South Korea.

tion. At that time, my firm with a good renown was able to transact with them. My firm provided them with the services that they desired and added three or more services beyond their needs. Gradually, they began to give my firm a great deal of information and introduce us to their branches. Thanks to the international firms, my trading period and scale have increased and the interdependence has grown, whereas uncertainty has disappeared. As the result of these effects, we have constructed a high trust level, changing from a short-term and unequal relationship to a long-term and equal one" (Nam-gu in Busan, November 2008).

\section{Conclusions}

This study has examined the relationships among trust levels, their determinants, and spatial dimensions between firms in the warehousing industry. We defined the trust levels and development stages in inter-firm relationships and investigated the determinants of the three trust levels and the relationships regarding the three trust levels. Furthermore, we analyzed the influences of the determinants and the spatial dimension differences by the trust levels between firms. This paper confirms these results:

First, a firm's environment, i.e. its reputation and renown, forms a relationship between firms; the trust level depends in part on the effects of its determinants under the inter-firm relationship. The lower the macro trust levels between firms, the more firms are affected by the culture and norm of firms \& formal institution due to the natural opportunistic behaviors of trading firms. Therefore, geographical proximity plays a vital role in improving the trust level from the macro level to the meso level by fostering frequent interaction between firms and gradually removing the uncertainty. Long-term and repeated interaction, information sharing and reciprocity, and interdependence and asset specificity greatly influence the creation of the micro level that makes up the high trust level between firms. When this process is repeated, the trust for partner firms becomes higher from their reputation and renown, which leads to the firms extending the spatial dimension of their activities.

Second, all of the trust levels are primarily created in the local space dimensions. They are closely correlated to the both dynamic and static agglomeration economics. That is, dynamic and static agglomeration economics generate an external economy for a firm's activities. The external economics of a firm's activities build inter-firm relationships based on a firm's environment, i.e. resource acquisition, technology or knowledge transfer, reputation, and renown. This implies that the appearance of various trust levels in the local dimension is the result from the external effect of a firm's activities.

Third, the higher the inter-firm trust levels are from the macro level to the meso level, and gradually to the micro level, the more the spatial dimensions of the relationships between firms expand from local to national and to international dimensions, respectively. The trust levels play an important role for a firm's globalization. If the firm has renown as the result of trust building, the firm has a high probability in building relationships with foreign firms.

These conclusions show the relationships among trust levels and the determinants, and spatial dimensions between firms. In other words, trust levels between firms are determined according to their determinants. The determined trust levels affect the spatial dimensions of the firm activities. Ultimately, trust levels between firms act as mediators between the determinants and spatial dimensions.

The major limitation of this paper is that the survey was practiced for only warehousing providers and not warehousing users. A further study needs to analyze a 
survey that includes both providers and users in order to achieve an objective generalization.

\section{REFERENCES}

[1] A. Darr and I. Talmud, "The Structure of Knowledge and Seller-Buyer Networks in Markets for Emergent Technologies,” Organization Studies, Vol. 24, No. 3, 2003, pp. 443-461. doi:10.1177/0170840603024003911

[2] B. Uzzi and R. Lancaster, "Relational Embeddedness and Learning: The Case of Bank Loan Managers and Their Clients,” Management Science, Vol. 49 No. 4, 2003, pp. 383-399. doi:10.1287/mnsc.49.4.383.14427

[3] G. A. Bigley and J. L. Pearce, "Straining for Shared Meaning in Organizational Science: Problems of Trust and Distrust," Academy of Management Review, Vol. 23, No. 3, 1998, pp. 405-422.

[4] P. Di Maggio and H. Louch, "Socially Embedded Consumer Transactions: For What Kinds of Purchases Do People Most Often Use Network?” American Sociological Review, Vol. 63, No. 3, 1998, pp. 619-637. doi:10.2307/2657331

[5] M. S. Mizruchi and L. B. Stearns, "Getting Deals Done: The Use of Social Networks in Bank Decision-Making," American Sociological Review, Vol. 66, No. 5, 2001, pp. 647-671. doi:10.2307/3088952

[6] B. McEvily, V. Perrone and A. Zaheer, "Trust as an Organizing Principle,” Organization Science, Vol. 14, No. 1, 2003, pp. 91-103. doi:10.1287/orsc.14.1.91.12814

[7] M. Carney, "The Competitiveness of Network Production: The Role of Trust and Asset Specificity,” Journal of Management Studies, Vol. 35, No. 4, 1998, pp. 457-479. doi:10.1111/1467-6486.00105

[8] M. Sako, "The Role of Trust in Japanese Buyer-Supplier Relationships,” Ricerche Economiche, Vol. 45, No. 2-3, 1991, pp. 449-474.

[9] M. Sako and S. Helper, "Determinants of Trust in Supplier Relations: Evidence from the Automotive Industry in Japan and United States," Journal of Economic Behavior and Organization, Vol. 34, No. 3, 1998, pp. 387-417. doi:10.1016/S0167-2681(97)00082-6

[10] S. Goran, "Perceived Trust towards Suppliers and Customers in Supply Chains of the Swedish Automotive Industry," International Journal of Physical Distribution \& Logistics Management, Vol. 31, No. 9-10, 2001, pp. 635650.

[11] R. Handfield and C. Bechtel, "Writing the Ideal Paper for JOM: A New Editor's Perspective,” Journal of Operations Management, Vol. 20, No. 1, 2002, pp. 10-18.

[12] I. W. Kwon and T. W. Suh, "Factors Affecting the Level of Trust and Commitment in Supply Chain Relationships," The Journal of Supply Chain Management, Vol. 40, No. 2, 2004, pp. 4-14. doi:10.1111/j.1745-493X.2004.tb00165.x

[13] S. L. Golicic, "A Comparison of Shipper and Carrier Relationship Strength,” International Journal of Physical Distribution \& Logistics Management, Vol. 37, No. 9,
2007, pp. 719-739. doi:10.1108/09600030710840831

[14] C. Niezen, W. Weller and H. Deringer, "Demanding Better Management,” Business Strategy Review, Vol. 18, No. 1, 2007, pp. 47-49. doi:10.1111/j.1467-8616.2007.00454.X

[15] M. Sambasivan and N. Y. Ching, "Strategic Alliance in a Manufacturing Supply Chain: Influence of Organization Culture from the Manufacturer's Perspective," International Journal of Physical Distribution \& Logistics Management, Vol. 40, No. 6, 2010, pp. 456-474. doi:10.1108/09600031011062191

[16] J. Bowen, "Moving Place: The Geography of Warehousing in the US," Journal of Transport Geography, Vol. 16, No. 6, 2008, pp. 379-387. doi:10.1016/j.jtrangeo.2008.03.001

[17] C. Quinn, "Warehouses Big Growth Trend in Exurbs," Atlanta Journal Constitution, No. 24, 2005, p. 3E.

[18] O. Klein, "Social Perception of Time, Distance, and High-Speed Transportation," Time and Society, Vol. 13 No. 2-3, 2004, pp. 245-263. doi:10.1177/0961463X04043504

[19] R. M. Morgan and S. D. Hunt, "The Commitment-Trust Theory of Relationship Marketing," Journal of Marketing, Vol. 58, No. 3, 1994, pp. 20-38. doi:10.2307/1252308

[20] Y. Aoyama and S. J. Ratick, "Trust, Transactions, and Information Technologies in the US Logistics Industry,” Economic Geography, Vol. 83, No. 2, 2007, pp. 159-180. doi:10.1111/j.1944-8287.2007.tb00341.x

[21] M. Sako, "Prices, Quality and Trust: Inter-Firm Relation in Britain and Japan,” Cambridge University Press, Cambridge, 1992.

[22] R. J. Lewicki and B. B. Bunker, "Developing and Maintaining Trust in Work Relationships,” In: R. M. Kramerand and T. R. Tyler, Eds., Trust in Organizations: Frontiers of Theory and Research, Sage Publications, London, 1996, pp. 114-139. doi:10.4135/9781452243610.n7

[23] J. T. Murphy, "Building Trust in Economic Space,” Progress in Human Geography, Vol. 30, No. 4, 2006, pp. 427-450. doi:10.1191/0309132506ph617oa

[24] M. A. Hitt, L. Bierman, K. Shimizu and R. Kochhar, "Direct and Moderating Effects of Human Capital on Strategy and Performance in Professional Service Firms: A Resource-Based Perspective,” Academy of Management Journal, Vol. 44, No. 1, 2001, pp. 13-28. doi:10.2307/3069334

[25] K. Knorr-Cetina and U. Bruegger, "Global Microstructures: The Virtual Societies of Financial Markets,” American Journal of Sociology, Vol. 107, No. 4, 2002, pp. 905950. doi: $10.1086 / 341045$

[26] E. J. Lawler, “An Affect Theory of Social Exchange," American Journal of Sociology, Vol. 107, No. 2, 2001, pp. 321-352. doi:10.1086/324071

[27] M. Emirbayer and V. Johnson, "Bourdieu and Organizational Analysis," Theory and Society, Vol. 37, No. 1, 2008, pp. 1-44. doi:10.1007/s11186-007-9052-y

[28] R. Axelrod, “The Evolution of Cooperation,” Basic Books, New York, 1984. 
[29] D. M. Krep, "Corporate Culture and Economic Theory," In: E. J. Alt and K. A. Shepsle, Eds., Perspective on Positives Political Economy, Cambridge University Press, Cambridge, 1990, pp. 90-143.

[30] P. S. Aulakh, M. Kotabe and A. Sahay, "Trust and Performance in Cross-Border Marketing Partnerships: Behavioural Approach,” Journal of International Business Studies, Vol. 27 No. 5, 1996, pp. 1005-1032. doi:10.1057/palgrave.jibs.8490161

[31] L. G. Zucker, "Production of Trust: Institutional Sources of Economic Structure, 1840-1920,” Research in Organizational Behavior, Vol. 8, 1986, pp. 53-111.

[32] J. Coleman, "Social Capital in the Creation of Human Capital,” American Journal of Sociology, Vol. 94, 1988, pp. 95-120. doi:10.1086/228943

[33] A. Parkhe, "Strategic Alliance Structuring: A Game Theoretic and Transaction Cost Examination of Interfirm Cooperation," Academy of Management Journal, Vol. 36, No. 4, 1993, pp. 794-829. doi:10.2307/256759

[34] J. H. Dyer, "Effective Interfirm Collaboration: How Firm Minimize Transaction Costs and Maximize Transaction Value,” Strategic Management Journal, Vol. 18, No. 7, 1997, pp. 535-556. doi:10.1002/(SICI)1097-0266(199708)18:7<535::AID-S MJ885>3.0.CO;2-Z

[35] Y. L. Doz and G. Hamel, “Alliance Advantage,” Harvard Business School Press, Cambridge, 1998.

[36] D. Shin and J. Lee, "Trust in Lean Production Systems: Lean Job Design and Sources of Workers': Trust in Management at Korean Automobile Plants," The Academy of Management Annual Conference, Chicago, August 6-11 1999.

[37] J. H. Dyer and H. Singh, "The Relational View: Cooperative Strategy and Sources of Interorganizational Competitive Advantage," Academy of Management Review, Vol. 23, No. 4, 1998, pp. 660-679.

[38] F. R. Dwyer, P. H. Schurr and O. Sejo, "Developing Buyer-Seller Relationship,” Journal of Marketing, Vol. 51, No. 2, 1987, pp. 11-27. doi:10.2307/1251126

[39] J. Buchanan, "From the Inside Looking out,” In: S. Michael, Ed., Eminent Economists: Their Life Philosophies, Cambridge University Press, Cambridge, 1992, pp. 98-
106.

[40] R. F. Lusch and J. R. Brown, "Interdependency, Contracting, and Relational Behavior in Marketing Channels,” Journal of Marketing, Vol. 60, No. 4, 1996, pp. 1938. doi:10.2307/1251899

[41] J. B. Heide and A. S. Miner, "The Shadow of the Future: Effects of Anticipated Interaction and Frequency of Contract on Buyer-Seller Cooperation," Academy of Management Journal, Vol. 35, No. 2, 1992, pp. 265-291. doi:10.2307/256374

[42] J. B. Heide and G. John, “Alliances in Industrial Purchasing: The Determinants of Joint Action in Buyer-Supplier Relationship,” Journal of Marketing Research, Vol. 27, No. 1, 1990, pp. 24-36. doi:10.2307/3172548

[43] O. E. Williamson, "Calculativeness, Trust, and EconomicOrganization,” Journal of Law and Economics, Vol. 36, No. 2, 1993, pp. 453-486. doi:10.1086/467284

[44] O. E. Williamson, "The Economic Institutions of Capitalism,” The Free Press, New York, 1985.

[45] G. Walker and D. Weber, "A Transaction Cost Approach to Make-or-Buy Decisions,” Administrative Science Quarterly, Vol. 29, No. 3, 1984, pp. 373-391. doi: $10.2307 / 2393030$

[46] P. Cooke and K. Morgan, "The Associational Economy: Firms, Regions and Innovation,” Oxford University Press, Oxford, 1998.

[47] M. Granovetter, "Economic Action and Social Structure: The Problem of Embeddedness," American Journal of Sociology, Vol. 91, No. 3, 1985, pp. 481-510. doi:10.1086/228311

[48] M. Smitka, "Competitive Ties: Subcontracting in the Japanese Automotive Industry,” Columbia University Press, New York, 1991.

[49] P. DiMaggio and W. W. Powell, "Iron-cage Revisited: Institutional Isomorphism and Collective Rationality in Organizational Fields," American Sociological Review, Vol. 48, No. 2, 1983, pp. 147-160.

[50] D. Sirdeshmukh, J. Singh and B. Sabol, "Consumer Trust, Value, and Loyalty in Relational Exchanges,” Journal of Marketing, Vol. 66, No. 1, 2002, pp. 15-37. doi:10.1509/jmkg.66.1.15.18449 